\title{
MEMBANGUN APLIKASI MANAJEMEN PENJUALAN DAN PEMESANAN MAKANAN PADA TWO D COFFEE ROASTERY
}

\author{
Nita Rahmawati ${ }^{1}$, Muhammad Soleh Ritonga ${ }^{2}$ \\ ${ }^{1,2}$ Teknik Informatika, Fakultas Teknik dan Ilmu Komputer, Universitas Indraprasta PGRI Jakarta \\ Jalan Raya Tengah No 80, Kelurahan Gedong, Pasar Rebo, Jakarta Timur \\ 1nita.rahmawati08@gmail.com, 22soleh_0502@gmail.com
}

\begin{abstract}
ABSTRAK
Two D Coffee Roastery memiliki permasalahan yaitu proses pencatatan secara manual memerlukan tempat penyimpanan yang sangat luas, akibat kertas yang bertumpuk serta memerlukan waktu yang lama dalam proses pencarian kembali data. Selain itu, pelayanan terhadap pelanggan menjadi tidak efisien dan akan terjadi kesalahan akibat waktu yang lama dalam pencarian data. Tujuan merancang suatu aplikasi manajemen penjualan dan pemesanan makanan ini adalah untuk memudahkan admin dalam memproses pengolahan data yang ada saat ini. Perangkat aplikasi yang telah dibuat dengan bahasa pemrograman Java NetBeans 8.0.2 dan penyimpanan data pada database MySQL dapat memberikan kelancaran dalam proses menginput dan penyimpanan data-data serta laporan-laporan yang diberikan kepada Pimpinan kafe. Metode pengembangan sistem yang digunakan adalah Waterfall dalam penelitian ini dengan tahapan-tahapan seperti rekayasa sistem, analisis, desain, coding, testing, dan maintenance. Hasil dari penelitian ini adalah aplikasi yang dapat memproses data penjualan dan pemesanan berbasis desktop pada Two D Coffee Roastery secara terkomputerisasi dengan menggunakan bahasa pemrograman Java dan MySQL sebagai DBMS nya sehingga menghasilkan laporan yang tersimpan dengan baik dan memberikan hasil secara cepat dan akurat.
\end{abstract}

Kata Kunci: Aplikasi, Penjualan, Pemesanan, Makanan

\begin{abstract}
Two D Coffee Roastery has a problem, namely the manual recording process requires a very large storage area, due to piles of paper and requires a long time in the process of retrieving data. In addition, service to customers becomes inefficient and errors will occur due to a long time in searching for data. The purpose of designing a sales and food ordering management application is to make it easier for admins to process the current data processing. Application tools that have been made with the Java NetBeans 8.0.2 programming language and data storage in the MYSQL database can provide smooth processing of input and storage of data and reports given to the cafe leadership. The system development method used is Waterfall in this study with stages such as systems engineering, analysis, design, coding, testing, and maintenance. The result of this research is an application that can process sales and ordering data based on a desktop on a computerized Two D Coffee Roastery using the Java programming language and MySQL as the DBMS so as to produce reports that are stored properly and provide results quickly and accurately.
\end{abstract}

Key Word: Application, Sale, Ordering, Food

\section{PENDAHULUAN}

Perkembangan arus globalisasi yang diiringi dengan perkembangan teknologi informasi menyebabkan arus informasi yang dulunya sulit didapat kini dapat dengan mudah diperoleh sesuai dengan kebutuhan (Sholikhah, Sairan, \& Syamsiah, 2017). Perkembangan teknologi yang semakin maju menuntut suatu kinerja dalam sebuah instansi atau perusahaan yang relatif cepat dan tepat untuk menghasilkan informasi yang dibutuhkan (Nugraha, 2014). Salah satunya penerapan teknologi komputer sebagai alat bantu yang mutlak dipergunakan sebagai pendukung utama dalam persaingan bisnis dan dukungan sumber daya manusia yang baik. Untuk dapat menciptakan dan menghadapi kondisi yang demikian, perlu adanya sistem informasi yang dapat membantu dalam memudahkan segala proses yang dibutuhkan oleh perusahaan (Sari, 2017).

Kafe yang sering juga disebut coffee house, coffee shop, atau cafe, merupakan istilah yang digunakan untuk tempat yang melayani pesanan kopi atau minuman hangat lainnya. Kafe memiliki karakteristik seperti bar atau restoran, tapi berbeda dengan kafetaria. Banyak kafe yang tidak hanya menyediakan kopi, tetapi juga teh bersama dengan makanan ringan, namun ada juga kafe dan resto yang merupakan kafe yang dilengkapi dengan makanan utama (bukan manakanan ringan). Dari sisi budaya, kafe telah tersebar luas untuk menjadi pusat interaksi 
sosial dimana orang-orang dapat berkumpul, berbicara, menulis, membaca, melawak, atau sekedar mengisi waktu (Rismaniah, Widianto, \& Setiyorini, 2020).

Two D Coffee Roastery merupakan salah satu unit usaha yang bergerak dibidang makanan. Pada saat ini Two D Coffee Roastery mengalami kesulitan dalam melayani pemesanan dan masih menggunakan pencatatan yang belum terkomputerisasi atau masih menggunakan sistem konvesional. Dimana pelayan mengalami kesulitan dalam mencatat pemesanan pelanggan yang dilakukan secara manual menggunakan kertas sehingga sering sekali mengalami keterlambatan untuk melakukan pelaporan kepada pemilik kafe. Dan ada pula permasalahan didalam pendataan proses transaksi penjualan karena semuanya dikerjakan secara manual tidak adanya suatu sistem informasi sebagai penunjang proses tersebut.

Dengan permasalahan tersebut, perlu adanya suatu sistem yang terkomputerisasi dalam penyelesaiannya. Sistem adalah sekelompok unsur yang erat hubungannya satu dengan yang lain, yang berfungsi bersama-sama untuk mencapai tujuan (Sutabri, 2012). Sistem merupakan suatu kumpulan dari komponenkomponen yang membentuk satu kesatuan (Tyoso, 2016). Pembangunan sistem adalah sekumpulan aktivitas yang menggambarkan secara rinci bagaimana sistem akan berjalan. Hal itu bertujuan untuk menghasilkan produk perangkat lunak yang sesuai dengan kebutuhan user (Satzinger, J. W., Jackson, R. B., Burd, n.d.).

Diharapkan dengan adanya suatu sistem informasi dapat menangani permasalahan yang ada di perusahaan tersebut. Sistem adalah setiap sesuatu terdiri dari obyek-obyek, atau unsurunsur, atau komponen-komponen yang bertata kaitan dan bertata hubungan satu sama lain, sedemikian rupa sehingga unsur-unsur tersebut merupakan satu kesatuan pemrosesan atau pengolahan yang tertentu. (Prasojo, 2011)

Dirancanganya suatu aplikasi ini dapat memudahkan pekerjaan Admin dalam melaksanakan pembuatan laporan dan dapat memudahkan Two D Coffee Roastery dalam proses pendataan serta transaksi penjualan.

\section{METODE PENELITIAN}

Peneliti menggunakan metode Research and Development dalam penyelesaian penelitian ini. (Sugiyono, 2016). Dalam pelaksanaan R\&D, ada beberapa metode yang digunakan yaitu metode deskriptif, evaluatif dan eksperimental. Metode penelitian deskriptif digunakan dalam penelitian awal untuk menghimpun data tentang kondisi yang ada yaitu penulis membutuhkan datadata yang dapat menunjang tercipta nya suatu sistem informasi penjualan dan pemesanan makanan seperti data makanan dan minuman, data penjualan, data pemesanan dan data stok data makanan dan minuman terdahulu yang masih tersimpan secara manual didalam buku besar. Metode evaluatif digunakan untuk mengevaluasi proses ujicoba pengembangan suatu produk, dalam proses ini penulis melakukan ujicoba terhadap suatu sistem yang telah dirancang agar tidak ada terjadi kesalahan dalam proses penginputan data serta pelaporan bulanan kepada pemilik kafe. Dan metode eksperimen digunakan untuk menguji keampuhan dari produk yang dihasilkan, dalam proses yang terakhir ini perlu dilakukan pengujian akhir yang diharapkan bahwa sistem yang dirancang oleh penulis dapat berjalan dengan baik dan sesuai dengan kebutuhan dan terfokus pada proses penjualan dan pemesanan pada Two D Coffee Roastery.

Penulis mempelajari dan mengamati prosesproses yang terdapat pada Two D Coffee Roastery yang beralamat di Jl. Mochammad Kahfi 1 Jl. Kp. Kandang No.26B, RT.10/RW.6, Jagakarsa, Kec. Jagakarsa, Kota Jakarta Selatan, Daerah Khusus Ibukota Jakarta 12620. Pada bulan Maret 2021 sampai dengan bulan Juli 2021, prosesnya antara lain:

1) Proses Penjualan

Penulis mengamati proses penjualan pada Two D Coffee Roastery mulai dari kedatangan pelanggan sampai dengan proses penjualan di Two D Coffee Roastery.

2) Proses Pemesanan

Penulis mengamati proses pemesanan makanan pada Two D Coffee Roastery.

3) Proses Stok Makanan dan Minuman Penulis mengamati proses stok data makanan dan minuman yang ada di Two D Coffee Roastery.

4) Proses Pembuatan Laporan

Penulis mengamati proses pembuatan laporan yang dilakukan oleh bagian administrasi, mulai 
dari pengecekan laporan sampai dengan cetak laporan.

\section{HASIL DAN PEMBAHASAN \\ Analisa Permasalahan}

Sistem informasi manajemen penjualan dan pemesanan makanan di Two D Coffee Roastery masih tergolong sederhana. Pencatatan data penjualan dilakukan secara manual. Pencatatan data pembelian dan penjualan berdasarkan penulisan tangan, sehingga akan terjadi kemungkinan adanya kesalahan didalam pembuatan laporan (Ananda \& Zuraidah, 2019). Begitu pula dalam hal penyimpanan data, data tersimpan dalam map dan akan dilemari arsip.

Dari pembahasan diatas penulis mengambil simpulan atas permasalahan yang ada diantaranya:

1. Penulisan data masih dilakukan secara manual dalam pencatatan data penjualan makanan maupun dalam pembuatan laporan.

2. Proses pencatatan secara manual memerlukan tempat penyimpanan yang sangat luas, akibat kertas yang bertumpuk serta memerlukan waktu yang lama dalam proses pencarian kembali data.

3. Pelayanan terhadap pelanggan menjadi tidak efisien dan mungkin akan terjadi kesalahan akibat waktu yang lama dalam pencarian data.

\section{Alternatif Penyelesaian Masalah}

Dalam mencari solusi permasalahan yang ada maka penulis membuat suatu sistem yang akan membantu dalam menyelesaikan masalah tersebut. Disini penulis membuat suatu sistem aplikasi yang akan memudahkan admin dalam bertransaksi dan memudahkan manajer dalam memonitoring, mengambil keputusan serta mendapat laporan.

Berdasarkan analisis sistem yang sedang berjalan saat ini penulis melihat kelemahankelemahan dan pokok permasalahan yang terdapat pada sistem aplikasi manajemen penjualan dan pemesanan makanan pada Two $\mathrm{D}$ Coffee Roastery, maka penulis dapat menyarankan beberapa alternatif permasalahan yang dapat dicoba, yaitu:

1. Agar tidak terjadi keterlambatan didalam proses pengerjaan informasi, sebaiknya dikoordinasi dengan baik dan terkomputerisasi dengan benar antara sub sistem yang satu dengan yang lainnya, dan sebaiknya Two D Coffee Roastery membuat rancangan sistem yang dapat meringankan dalam bertransaksi, membuat laporan, mengecek data-data khususnya pada penjualan.

2. File atapun data yang sudah dikerjakan sebaiknya disimpan ke Harddisk ataupun alat penyimpanan data yang lain, dan jika perlu dibuat backupnya jika saat teradi kesalahan memiliki cadangan file ataupun data-data.

3. Alangkah baiknya bila komputer yang digunakan untuk memproses data di upgrade, sehingga pemrosesan data tersebut dapat dilakukan lebih baik, cepat dan tepat.

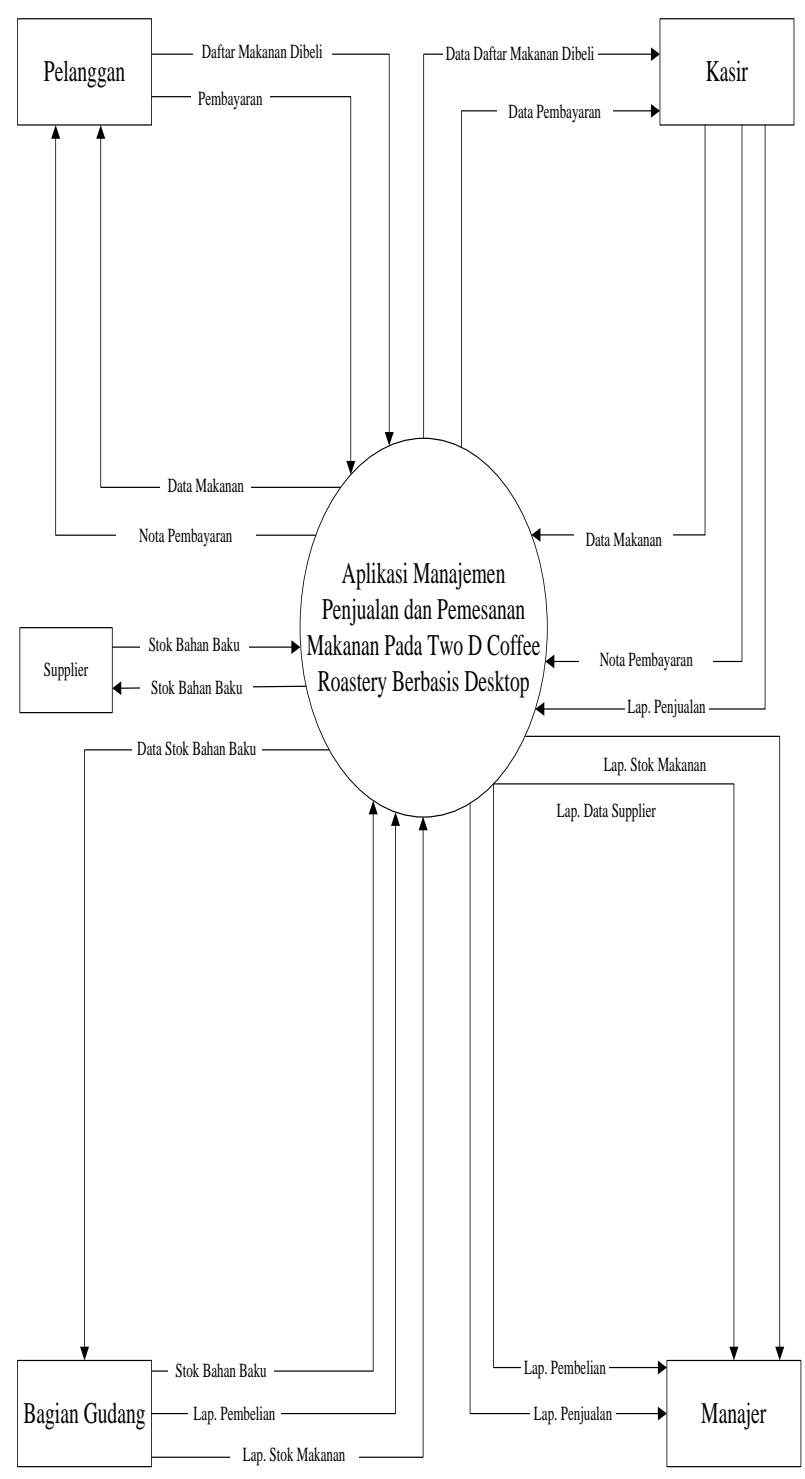

Gambar 1. Diagram Konteks 


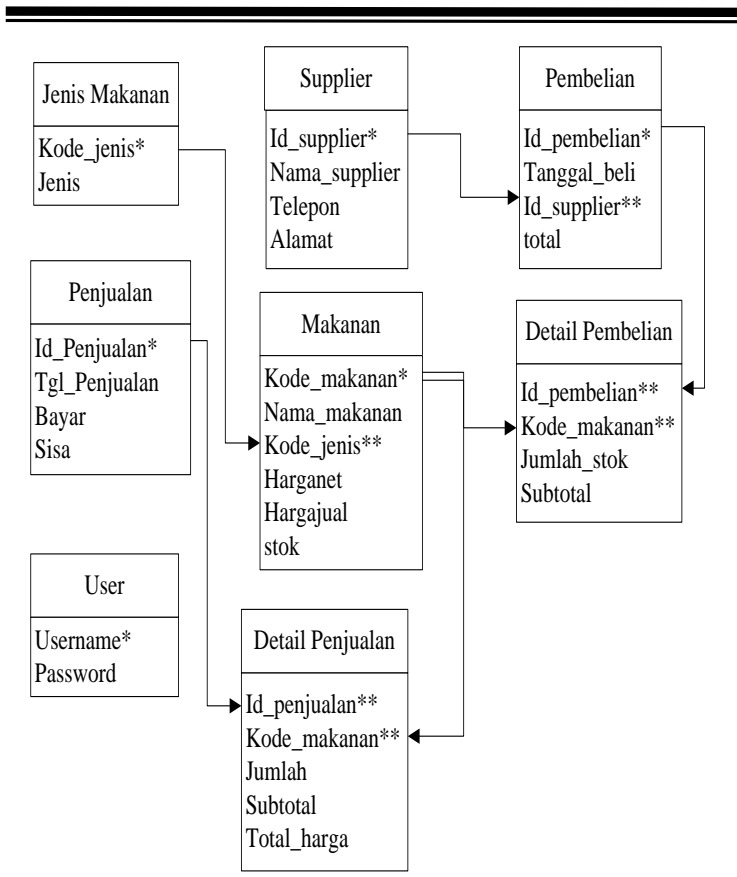

Gambar 2. Normalisasi

Berikut adalah tampilan layar dan hasil pengujian pada software program yang telah di buat dengan bahasa pemrograman Java.

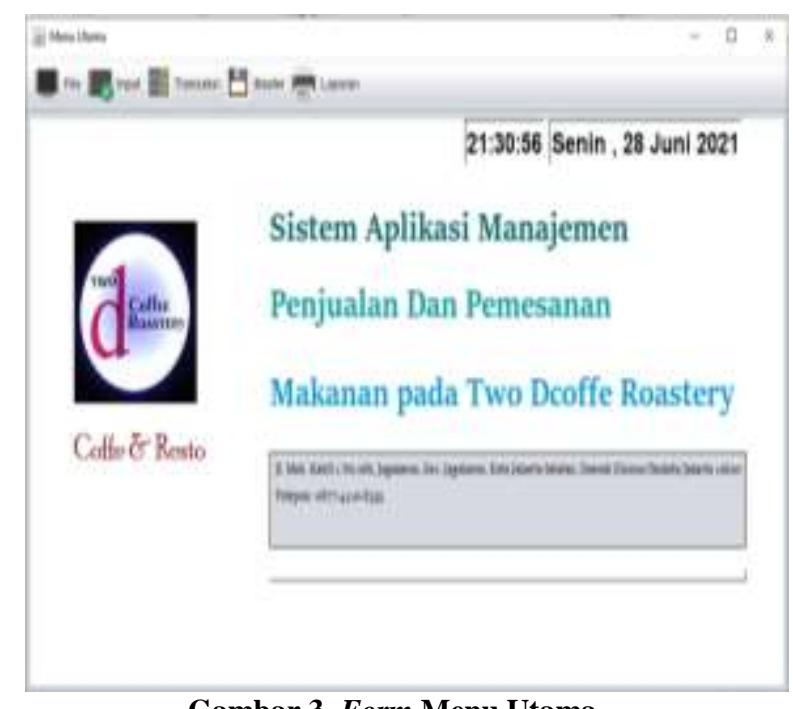

Gambar 3. Form Menu Utama

Layar di atas menampilkan tampilan Menu Utama pada Aplikasi Penjualan dan Pemesanan Makanan pada Two D Coffee Roastery. Pada layar utama tersedia menu bar yang terdiri dari master data yang digunakan untuk memasukkan data yang berkaitan dengan data jenis makanan, jenis minuman, data makanan, data minuman, data supplier, data pembelian, data penjualan, dan laporan-laporan.

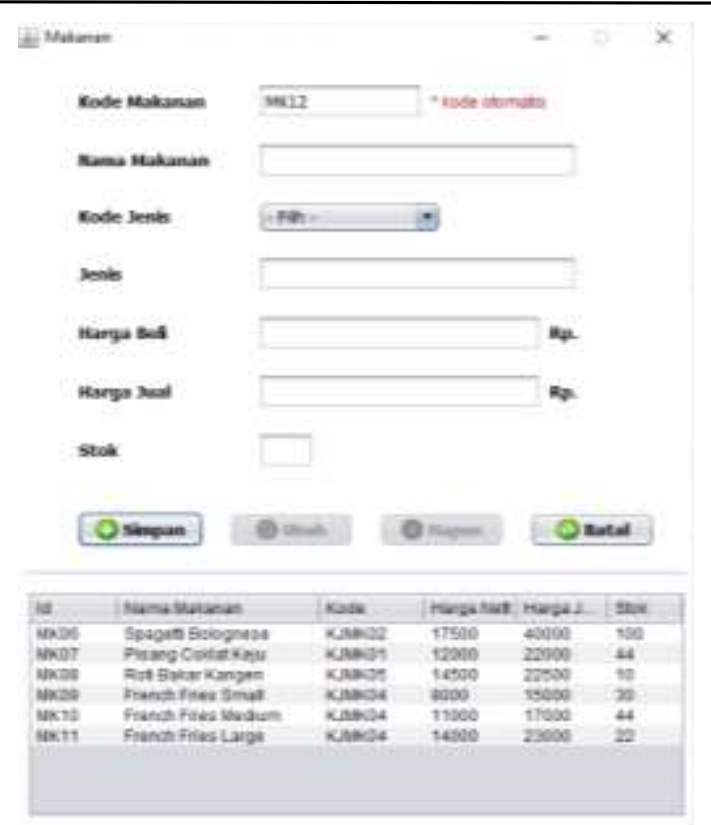

Gambar 4. Form Data Makanan

Layar di atas menampilkan tampilan form data makanan. Pada layar form data makanan untuk meng-input data makanan yang terdiri dari Kode Makanan, Nama Makanan, Kode Jenis, Jenis Makanan, Harga Beli, Harga Jual dan Stok.

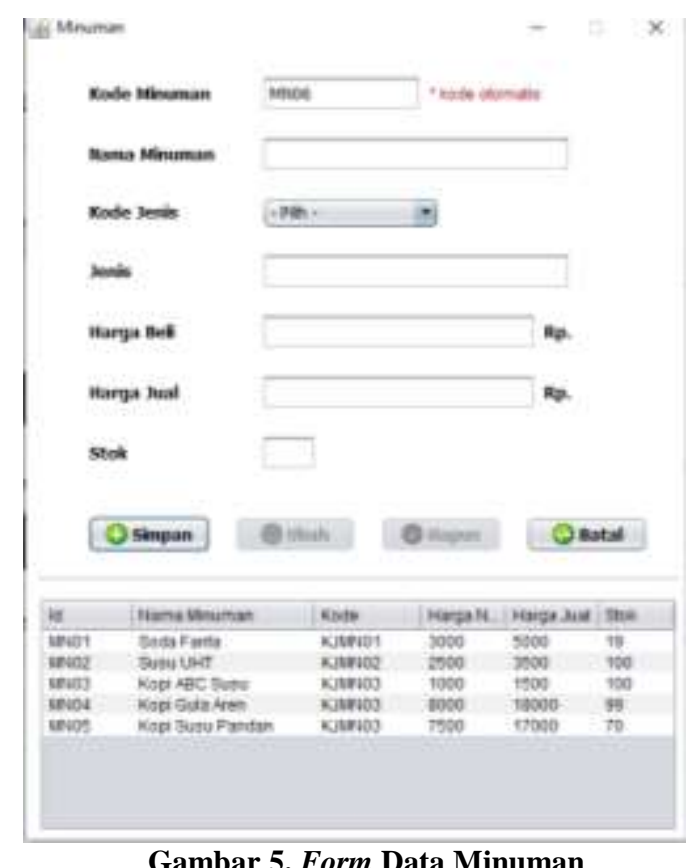

Layar di atas menampilkan tampilan form data minuman. Pada layar form data minuman untuk meng-input data minuman yang terdiri dari Kode Minuman, Nama Minuman, Kode Jenis, Jenis Minuman, Harga Beli, Harga Jual dan Stok. 


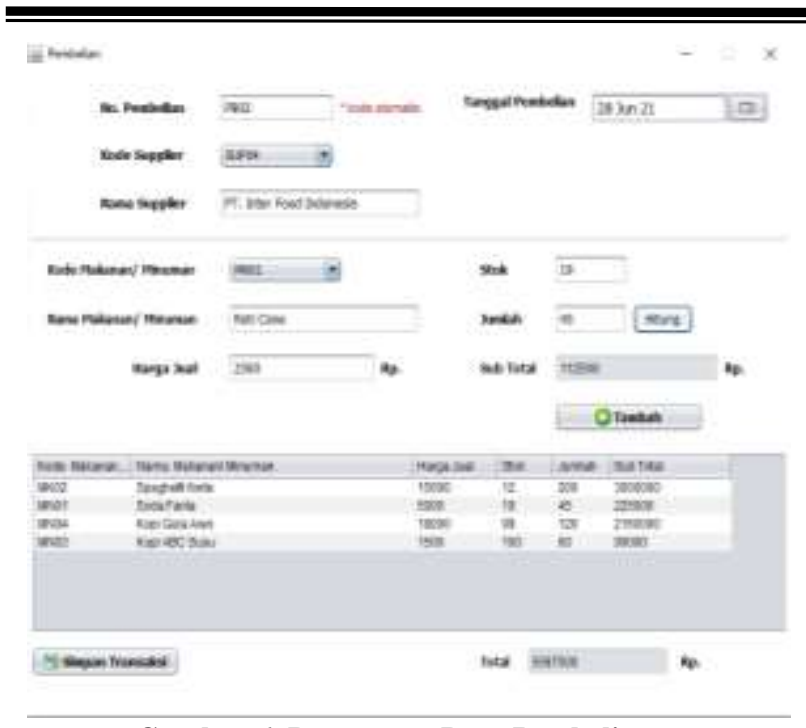

Gambar 6. Data Form Data Pembelian

Layar di atas menampilkan tampilan form data transaksi pembelian. Pada layar form data transaksi pembelian untuk meng-input data transaksi pembelian yang terdiri dari No Pembelian, Tgl Pembelian, Kode Supplier, Nama Supplier, Kode Makanan/Minuman, Nama Makanan/Minuman, Harga Jual, Stok, Jumlah dan Sub Total.

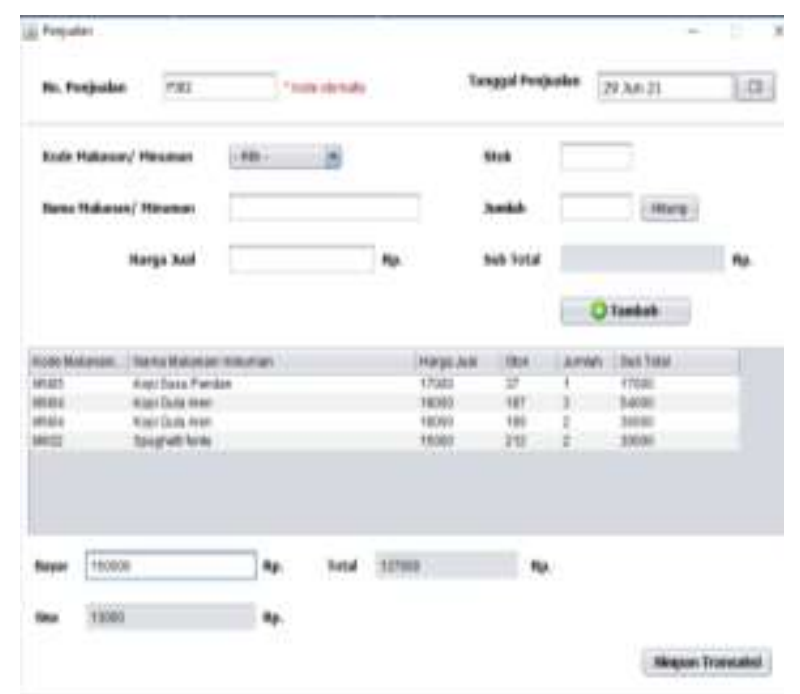

Gambar 7. Laporan Data Transaksi Penjualan

Layar di atas menampilkan tampilan form data transaksi penjualan. Pada layar form data transaksi penjualan untuk meng-input data transaksi penjualan yang terdiri dari No Penjualan, Tgl Penjualan, Kode Makanan/Minuman, Nama Makanan/Minuman, Harga Jual, Stok, Jumlah dan Sub Total.

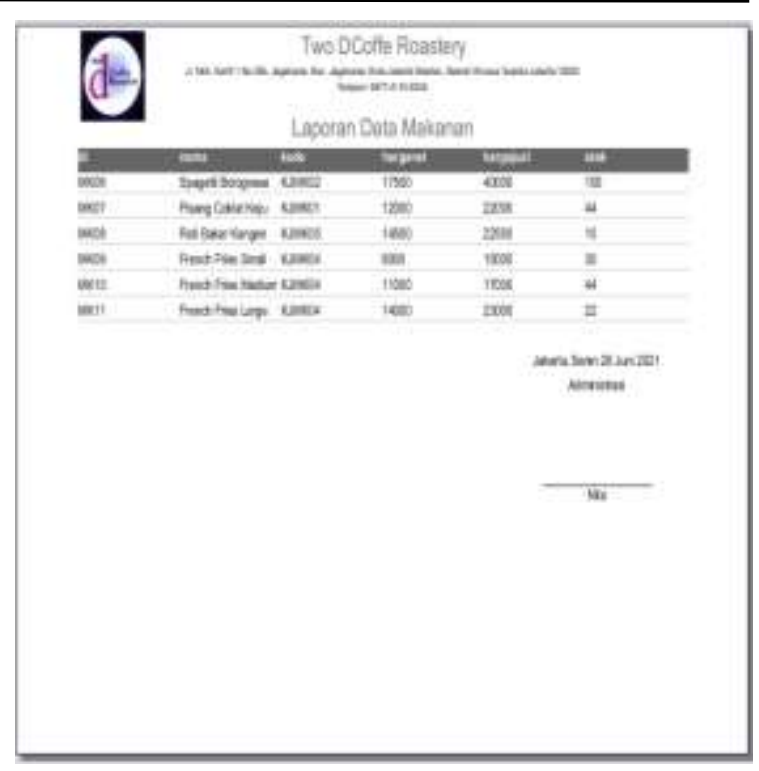

Gambar 8. Laporan Data Makanan

Layar di atas menampilkan tampilan form laporan data makanan. Pada layar form data makanan digunakan untuk mengecek laporan data makanan terdiri Kode Makanan, Nama Makanan, Kode Jenis, Jenis Makanan, Harga Beli, Harga Jual dan Stok.

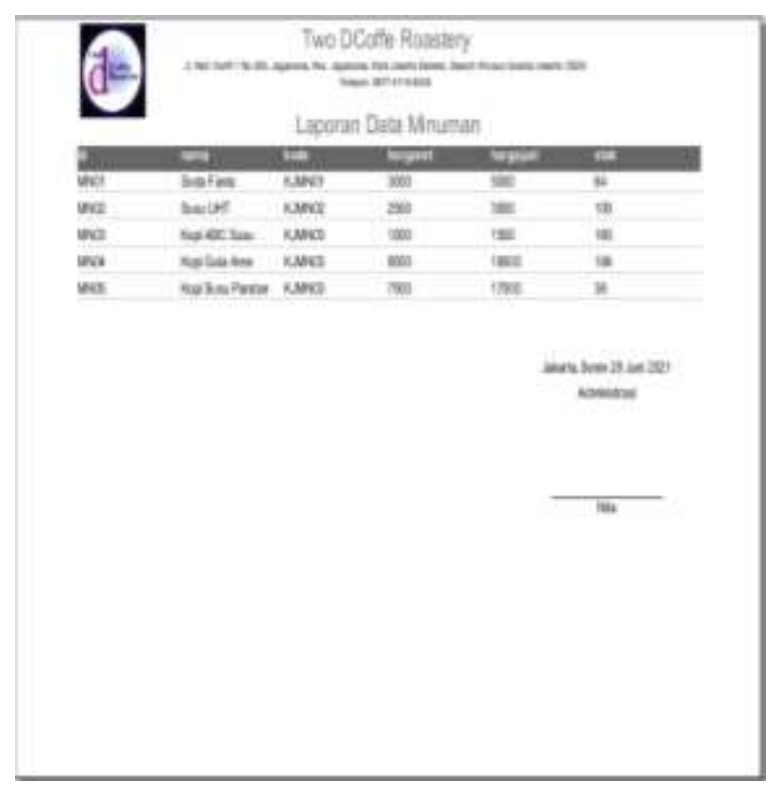

Gambar 9. Laporan Data Minuman

Layar di atas menampilkan tampilan form laporan data minuman. Pada layar form data minuman digunakan untuk mengecek laporan data minuman terdiri Kode Minuman, Nama Minuman, Kode Jenis, Jenis Minuman, Harga Beli, Harga Jual dan Stok. 


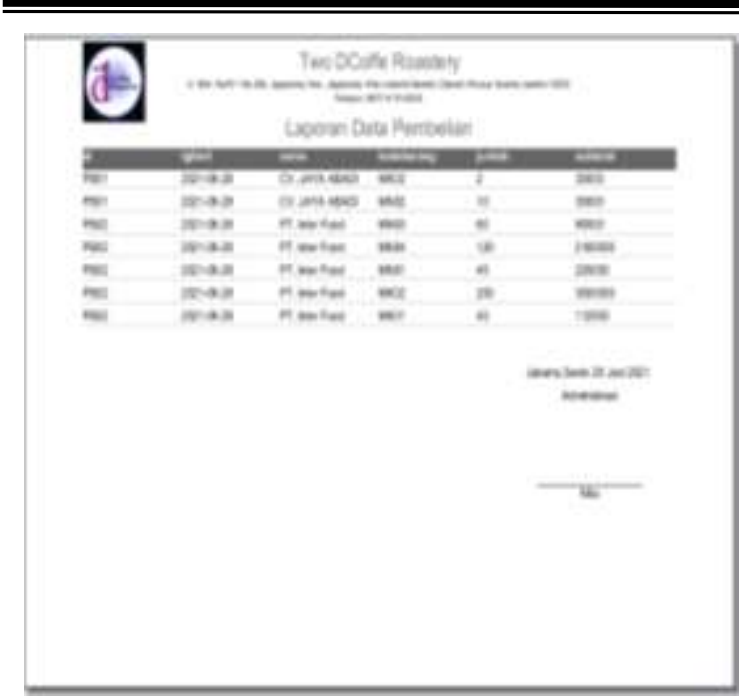

Gambar 10. Laporan Data Pembelian

Layar di atas menampilkan tampilan form laporan data pembelian. Pada layar form data pembelian digunakan untuk mengecek laporan data pembelian terdiri No Pembelian, Tgl Pembelian, Kode Supplier, Nama Supplier, Kode Makanan/Minuman, Nama Makanan/Minuman, Jumlah dan Sub Total.

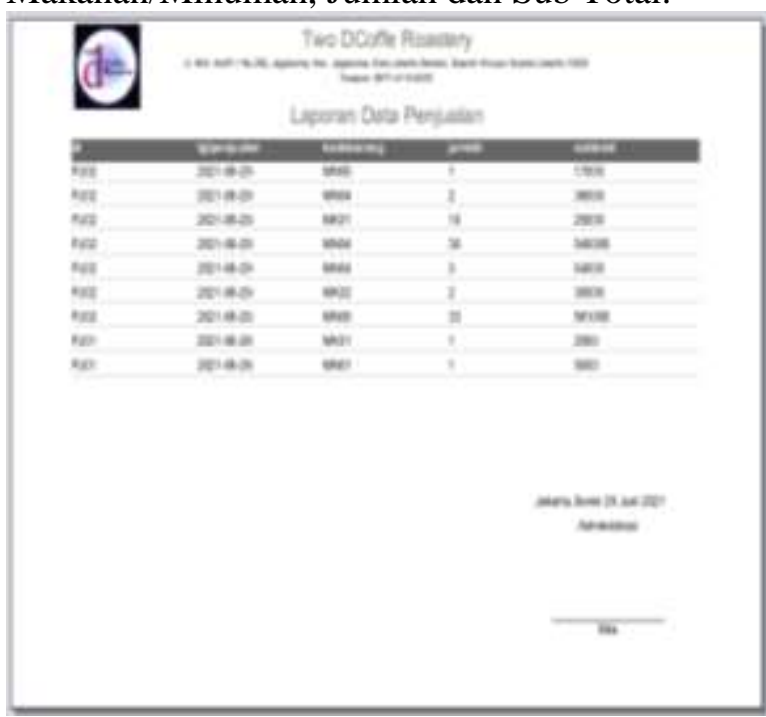

Gambar 11. Laporan Data Penjualan

Layar di atas menampilkan tampilan form laporan data penjualan. Pada layar form data penjualan digunakan untuk mengecek laporan data penjualan terdiri No Penjualan, Tgl Penjualan, Kode Makanan/Minuman, Jumlah dan Sub Total.

\section{SIMPULAN DAN SARAN}

Aplikasi ini sudah layak digunakan untuk proses manajemen penjualan dan pemesanan makanan pada Two D Coffee Roastery karena sudah sesuai dengan kebutuhan, sehingga dapat mempermudah admin dalam proses penginputan data, pencarian data serta pembuatan laporan.

Disarankan bagi peneliti selanjutnya, hasil penelitian ini bisa digunakan sebagai bahan perbandingan dan referensi untuk penelitian, dan sebagai bahan pertimbangan untuk lebih memperdalam penelitian selanjutnya sehingga proses manajemen penjualan serta pemesanan makanan agar bisa lebih efektif dan real-time.

\section{DAFTAR PUSTAKA}

Ananda, I., \& Zuraidah, E. (2019). Perancangan Sistem Informasi Penjualan Barang Pada PT Asia Truk Pratama Jakarta. Jurnal Informatika. https://doi.org/10.31311/ji.v6i2.6248

Nugraha, D. W. (2014). Sistem Informasi Penjualan Makanan Khas Kota Palu Berbasis Web. Jurnal Teknik Informatika, $7(2)$, 68-74. https://doi.org/10.15408/jti.v7i2.1950

Prasojo, M. (2011). Pengantar Sistem Informasi Manajemen. bandung: CV. Remadja Karya.

Rismaniah, R., Widianto, K., \& Setiyorini, T. (2020). Sistem Informasi Penjualan Makanan Dan Minuman Di Wejie Kopi Berbasis Web. Information Management For Educators And Professionals: Journal of Information Management, 5(1), 55. https://doi.org/10.51211/imbi.v5i1.1402

Sari, Y. P. (2017). Rancang Bangun Aplikasi Penjualan Dan Persediaan Di Kota Prabumulih. Jurnal Sistem Informasi Dan Komputerisasi Akuntansi (JSK).

Satzinger, J. W., Jackson, R. B., Burd, S. D. (n.d.). System Analysis and Design in A Changing World. USA: Cengage Learning.

Sholikhah, I., Sairan, M., \& Syamsiah, N. O. (2017). Aplikasi Pembelian Dan Penjualan Barang Dagang Pada CV Gemilang Muliatama Cikarang. Teknik Komputer AMIK BSI, III(1), 16-23.

Sugiyono. (2016). Metode Penelitian Kuantitatif, Kualitatif dan $R \& D$. Bandung: PT Alfabet.

Sutabri, T. (2012). Analisis Sistem Informasi. Yogyakarta: Andi.

Tyoso, J. S. P. (2016). Sistem Informasi Manajemen. Yogyakarta: DeePublish. 